\title{
EXOGENOUS CHANGES OF THE INDICATOR MINERALS AT THE FORMATION OF MINERALOGICAL HALOS OF KIMBERLITE BODIES.
}

Afanas'ev, V.P.; Sobolev, N.V. and Pokhilenko, N.P.

During the mineralogical halos formation the kimberlite minerals are affected by the powerful exogenous factors changing both individual minerals and the composition of mineral associations. The main factors of exogenous changes are mineral transportation during the mineral halos formation and physical-chemical changes in the formed sediments.

The changes during the process of transportation are expressed in two forms - i.e. the hydraulic grading of the transportation of the minerals of different density and proporcional to the value of their hydraulic fall diameter (the velocity of the free fall of the minerals in the aqueous medium, $\mathrm{m} / \mathrm{sec}$ ). The expressions for the fall diameter determination are obtained on the experimental basis: diamond $-\mathrm{V}=62,3 \cdot \mathrm{p}^{0,24}$, pyrope $-\mathrm{V}=61,6 \cdot \mathrm{p}^{0,23}$, picroilmenite $-\mathrm{V}=69,2 \cdot \mathrm{p}^{0,24}$, chromespinel $-\mathrm{V}=71,3 \cdot \mathrm{p}^{0,23}$. On their basis the coefficients of the mineral inertness for the plain rivers conditions (Yakultia) are calculated.

Another aspect of the mineral transportation is a decrease in their concentration with the removal from a kimberlite body. The hydraulic gradient and the distribution of the mineral concentration relative to the kimberlite body is expressed by the formulae in the idealized form:

$$
P=P o-B X P=P o e^{-B X}
$$

where $\mathrm{X}$ - is the distance up to kimberlite body, B - the coefficient of the mineral inertness, Po - the mineral concentration in kimberlite body elluvium, $\mathrm{P}$ - the mineral concentration at a distance $\mathrm{X}$.

The mechanical wearing depends mainly on the landscape dynamic conditions. Under the alluvial conditions on the continent, the kimberlite minerals are weakly rounded, on minerals larger than $2 \mathrm{~mm}$, the signs of rounding appear at a distance of some dozens of kilometers. The smaller ones are transported with no rouding to many dozens of kilometers. The minerals assume the medium level of rounding at wearing under the conditions of littoral alluvial plains which could be periodically flooded by the shallow basin waters and the minerals could be rounded under the influence of waves. The minerals are rounded to the maximum extent under the littoral conditions in the process of forth/back moviments under the wave influence, the minerals of the medium and high level of rounding are widely spread in the ancient mineral halos at the different regions of the world. The alluvial conditions are unfavorable for the good hydraulic grading of minerals. The best grading takes place under littoral conditions. Here the formation of the diamond-pyrope association with the similar grain sizes occurs and the mineral concentration grows, therefore, the rich diamond placers could be formed under the given conditions. Besides, according to the calculations and experimental data, the picroilmenite mechanical stability is approximately twice lower than of pyrope. Therefore, whether pyrope ultimetly rounded, than picroilmenite could be destroied completly. Diamonds are also rounded under these conditions.

The physical-chemical changes occur after fixation of the minerals in the sediments. Four main types of changes are discovered, i.e. under the condition of hypergenesis, diagenesis, metagenesis and metasomatosis. 
The hypergenous changes connected with the crust of weathering are widely spread in all parts of the world. The maximum changes are connected with the upper part of the crust of weathering profile, i.e. the hydrogenesis zone. According to the degree of stability the main deep-seated kimberlite minerals form series: diamond - zircon - chromespinel - picroilmenite - pyrope - clinopyroxene - olivine. Diamond and zircon are practically unchangeable. Olivine is completly destroyed, the grains of chromediopside are seldom preserved. Pyrope reveals specific features of the hypergen dissolution. It is poorly imperfect grains at dissolution acquire the form od cuboid with the proeminent faces which represent the dissolution equilibrium form. The spontaneous corrosion cracking occurs. During the experiments and the study of the mineral halos has been discovered that the pyrope resistance to dissolution is greatly dependent on the chemical composition. The orange low chromous pyropes being the least stable, their fractions in the halos decreases and the fraction of the violet chromous pyrope increases under hypergenic conditions respectively.

Picroilmenite under the hypergenic conditions is dissolved or it is substituted by leucoxene.

Chromespinel is not dissolved, its changes are connected with the appearance of microcracks at the surface which are due to the effect of spontaneous corrosion cracking.

Diagenesis slightly influences the kimberlite minerals. The main form of changes is corrosion cracking, mainly of pyrope and picroilmenite.

The changes under metagenesis and metasomatosis are not so widely spread as hypergenesis or diagenesis ones, but their influence on the minerals could be very significant. Metageneous changes in minerals occur during the orogeny processes. They are traced in the minerals from the triassic deposits of the Verkhoyansk folded zone along the right bank of the Lena river and in the Middle Devonian deposits in the Urals. In both cases pyrope cracks and it is substituted by chlorite. The pyramidal-tiled relief formed under the chlorite over the pyrope surface. In the Ural Devonian deposits the picroilmenite cracks and it is replaced by anatase. Chromespinel behaviour is not studied. Pyrope and picroilmenite could be completly destroyed under the given conditions replacing by the secondary minerals.

The metasomatic changes of the kimberlite minerals are connected with the influence of the intrusions of the differentiated traps. In the metasomatosis zone pyrope is substituted by chlorite with the formation of pyramidal-tiled relief like at the metagenesis. Picroilmenite is substituted by the anatase crystals, chromespinel assumes cavernous relief. Diamond under such conditions is unstable and it oxidizes forming oxidizing dissolution-trigontrioctahedroid. In the zone of maximum metasomatic changes the kimberlite minerals, including diamond, could be completly destroyed.

Thus, the complex of the exogenous changes of the kimberlite minerals strongly influences the composition of the mineral association, mineral concentration and their habit. The specific character of both mechanical and physical-chemical changes permits to solve the inverse problem i.e. according to the mineral habit to determine the conditions under which they were and on this basis to clear up the history of the development of the mineral halos. 